\title{
Language and Communication: A Matter of Intercultural Competence?
}

\author{
Maria Rosaria Nava, PhD \\ Lumsa University Rome Italy, Via della Traspontina, 21 - 00193 Rome, Italy \\ Email: mariarosarianava@yahoo.it
}

\section{Doi:10.5901/ajis.2015.v4n3s1p217}

\begin{abstract}
Nowadays, language competences have a strategic role both to establish social relations and favour mental processes and logical/cognitive capacities. So, only language competences are not sufficient to determine the complete acquisition of a language because other dimensions need to be considered, such as the socio-cultural context, so that a specific communicative competence is necessary. Communication is what members of a culture use to share certain perspectives and visions, to follow beliefs, values, behaviours and make them known. Misunderstandings and communicative issues are often due to culture. Hymes (1988), introducing the concept of communicative competence, argued that we need to use our language appropriately with regard to the communicative context. Hymes (1972b) also affirmed that a person "acquires competence as to when to speak, when not, and as to what to talk about with whom, when, where, in what manner.". In other words, it is about showing our own linguistic competence off in a variety of communicative situations considering the sociocultural context at first. Being "variously competent" allows us to give clear and effective communication, mediating our social interactions. It becomes clear the relevant role of communicative and cultural elements in learning or speaking a language and that linguistic competence is strictly linked to intercultural communicative competence. The purpose of this paper is to contribute to a greater consideration of the concept of intercultural competence not only with regard to our ability to communicate appropriately but also to our cultural appropriateness.
\end{abstract}

Keywords: language, communication, intercultural competence, culture.

\section{Introduction}

Nowadays, people are continuously involved in social, cultural and interpersonal contacts and numerous dimensions need to be considered in order to avoid or limit misunderstandings and communicative issues. Language competences have a strategic role in our relations, language is the primary way people use to communicate and interact, and these dynamics represent a constant part of our everyday life. Through language we communicate our experiences, thoughts, meanings, intentions, feelings and identity. Having only appropriate language competences is not sufficient because communication is a complex process involving several elements: communication is what members of a culture use to share certain perspectives and visions, to follow beliefs, values, behaviours and make them known. Hymes (1988), introducing the concept of communicative competence, argues that we need to use our language appropriately with regard to the communicative context. Hymes also affirmed that a person "acquires competence as to when to speak, when not, and as to what to talk about with whom, when, where, in what manner". Bonvillain (2003), perfectly defined the relationship between language and communication, "language is the primary means of communication between people. (...) Language links interlocutors in a dynamic, reflexive process. We learn about people through what they say and how they say it; we learn about ourselves through the ways that other people react to what we say; and we learn about our relationships with others through the give-and-take of communicative interactions.". Language is our main link with the outside world: through it we can "reliably cause precise new combinations of ideas to arise in each other's minds." (Pinker, 2000). It becomes clear the relevant role of communicative and cultural elements during our interactions or in learning or speaking a language and it is also evident that the linguistic competence is strictly linked to the intercultural communicative competence. Brown (1989), affirms that "Language is the roadmap of culture. It tells you where its people come from and where they are going". The communicative, cultural, communal and social functions of a language are relevant and need a specific consideration. Firstly, language helps to preserve and transmit culture; secondly, it "links individuals into communities of shared identities" (Philipsen, 1989; in Cooper P.J., 2007); thirdly, it manages all human interactions, it serves as social identification aspect unifying speakers as members of a single speech community. In other words, it is about using our own linguistic competence in a variety of communicative situations considering the socio-cultural context at first. As we understand, language and culture are strictly linked: when we learned our native 
language, we also unconsciously learned our culture. Gudykunst and Kim (1995), affirmed that, "we communicate the way we do because we are raised in a particular culture and learn its language, rules, and norms". Sapir and Whorf (1956), claimed: "human beings do not live in the objective world alone (...) but are at the mercy of the particular language which has become the medium of expression for their society. (...) The fact is that the «real world» is unconsciously built up on the language habits of the group (...) we experience the world because the language habits of our community predispose certain choices of interpretation." In our relations and interactions, we could perfectly master the language but we also need to know that the way we see the world may not be the same as the way another culture does. Consequently, a different view of the world comes up when we come into contact with a speaker of a different language: communication cannot be considered only as a simple information exchange but it should be regarded for its capacity of creating and maintaining relations according to the encountered cultural context. Language and communicative competences refer also to a significant intercultural competence. The purpose of this paper is to contribute to a greater consideration of the concept of intercultural competence not only with regard to our ability to communicate appropriately but also to our cultural appropriateness.

\section{Language and Communication: A Cultural Relation}

Culture is a complex concept to be defined for its numerous hidden meanings. It is a set of beliefs, values, behaviours that are learnt and shared within a group; it includes language, communication style, practices, costumes and different perspectives about roles and relations. We belong to more than one culture that can be, for instance, social, professional or religious. Culture defines they way we see the world, affecting our interactions and perceptions, our verbal and nonverbal language, our identity. There is no doubt about the evident and complex relation between culture and communication. The specific meanings, symbols and value systems belonging to a culture, emerge and are known through communication. Morillas (2001) affirmed that, "humans communicate linguistically in a cultural environment that constrains the form and nature of communication. Culture constrains both what is acquired and how it is acquired. In turn, communicative processes shape the culture that is transmitted from generation to generation". According to Aldridge (2002) culture is, "the shared system of symbolic knowledge and patterns of behaviour, derived from speech communication (...)We learn cultural codes for social life, role expectations, common definitions of situations, and social norms in order to provide predictability and survival of the human species. Human language is the symbolic glue for human culture. Moreover, Haslett (1989) affirmed that "culture by definition is a shared, consensual way of life and sharing and consensus are made possible only by communication". It appears clear the strict relation linking culture, communication and language. As far as this relation is concerned, Valdes (1986) found that in order to become linguistically competent, it is necessary to be aware of ourselves as "cultural beings" in the process leading to explore our own cultural complexity. Accepting our own culture, "comes with the acceptance of their language and a greater willingness to let go of the binding ties of the native language and culture".

"There is an interrelationship between a language and its people and if cultural information is not taught as a part of communicative competence, complete communication cannot happen" (Alptekin, 2002). Language and culture are inseparable: beliefs, ideas and identities are communicated through the language. "Culture is about shared meanings. Meanings are produced and exchanged through language, which is the medium through which we «make sense» of things. Meanings can only be shared through language" (Hall, 1997).

Culture and communication affect each other. Communication itself always arises and happens within a culture. In other words, communication brings culture and inevitably influences its structure. Our own culture shows off through communication and vice versa culture teaches us how to behave and communicate appropriately. Hall and Hall (1990) defined culture as "a system for creating, sending, storing and processing information" and considered it as strictly linked to communication implying that culture is about our daily life. Communication allows the members of a culture to share, not in all aspects, certain perspectives and visions of the world. We experience, consciously or unconsciously, our culture every day. Culture predominantly enters the dynamics of communication because, when meeting or interacting with the others, it is fundamental to understand their meanings, values, behaviours in order to have a functional, reciprocal and effective dialogue. Consequently, the communicative relation becomes crucial in learning the cultural competence that arises when approaching and knowing other cultures through a process based on awareness, knowledge and capacity. The more people are "culturally competent", the easier it will be for them to reduce the cultural gap and favour understanding and sharing of linguistic and cultural elements. In fact, the development of an intercultural communicative competence is a process of dynamic and continuous learning implying a transformation of our identity during the interaction with different cultures. 


\section{The Concepts of Communicative Competence and Cultural Competence}

The concept of competence includes both the ability to act and the knowledge of the contexts where the action itself finalises. Boyatzis (1982) defines competences both as personal (self-awareness, self-management, adaptability, selfcontrol, conscientiousness), and social (social awareness, empathy, social capability). Being competent is not a state but rather a process consisting in the mobilisation of all our individual resources, personal, theoretical, procedural, experiential and social (Le Boterf, 2000).

As already mentioned, Hymes (1988), introducing the concept of communicative competence, argues that we need to use our language appropriately with regard to the communicative context. Hymes also affirmed that a person "acquires competence as to when to speak, when not, and as to what to talk about with whom, when, where, in what manner". Savignon (1972) considered competence "in terms of the expression, interpretation, and negotiation of meaning", taking into account also the socio-cultural and linguistic context. Different aspects need to be considered when speaking about the communicative competence because, as we have already affirmed, it is not sufficient to know the language but it is rather more important to know how to use the language as an action tool in different contexts. The concept that Hymes proposed can be integrated with various other competences: linguistic, paralinguistic, kinesics, proxemics, pragmatic and socio-cultural, that is the capacity to verify whether and to what extent a specific linguistic statement is appropriate in relation to the socio-cultural context of reference. In other words, it is about showing our own linguistic competence off in a variety of communicative situations considering the socio-cultural context at first. Therefore, the communicative competence becomes, "the ability to function in a truly communicative setting - that is, in a dynamic exchange in which linguistic competence must adapt itself to the total informational input, both linguistic and paralinguistic, of one or more interlocutors" (Savignon, 1972).

The nature of such competence is not static but rather dynamic, interpersonal and extensively defined by the socio-cultural context where the speaker is. It is also about being "socio-linguistically competent", being aware of the rules, norms and conventions at the base of an appropriate comprehension and use of the language in various sociolinguistic and socio-cultural contexts-

As far as the concept of cultural competence is concerned, Cross, Bazron, Dennis and Issacs (1989) claimed that "cultural competence is a set of congruent behaviours, attitudes, and policies that come together in a system, agency or among professionals and enable that system, agency or those professions to work effectively in cross-cultural situations. The word culture is used because it implies the integrated pattern of human behaviour that includes thoughts, communications, actions, customs, beliefs, values and institutions of a racial, ethnic, religious or social group. The word competence is used because it implies having the capacity to function effectively". Moreover, Mays, Siantz and Viehweg (2002) affirmed that "for the individual, the process of cultural competence involves becoming culturally aware, gaining cultural knowledge and achieving cultural skills". Certainly, this process requires the abandonment of ethnocentric attitudes and the increase of open behaviours, flexibility and non-judgmental perceptions (Stewart, 2006). Additionally, cultural competence can enhance empathy, awareness and allows us to understand and recognise that others may observe the world through different cultural lenses.

We can affirm that people, in order to become "culturally competent", should have a specific knowledge of behaviours, perceptions, attitudes, traditions and the language characterising a certain culture. They should also consider diversity as a value, being able to communicate effectively with people having a different cultural background. So, communication becomes a vital part of our social life: a specific and necessary competence to activate and develop social relations, characterised and driven by culture, beliefs, traditions, stereotypes, prejudices affecting their existence. Our cultural and communicative competence becomes mediator of these relations. These cultural differences, provoking also a clash of cultural identities, become indispensable in our life because within the actual multicultural society everybody measure up with each other to value their own cultural diversity. Culture is strongly responsible for building up our individual realities, our specific competences and our communicative behaviours. Intercultural competence is a bridge, a connection to the others, a necessary element to increase and encourage an effective communication among cultures.

\section{Intercultural Competence: A Bridge between Cultures}

The communicative and cultural competences contribute to intercultural awareness, skills, and know-how because within the globalized world intercultural contacts are greater and greater, and people need both to understand and negotiate differences through an effective communication. Communication among speakers of different languages is not just a matter of information exchange, it is also about understanding the perceptions and meanings arising from the other 
speaker, according to his/her cultural context. Engaging in the new cultural setting means both transcending and transforming our personal way of perceiving the reality and interacting within it.

The intercultural competence is considered as the capacity to communicate effectively in multicultural situations, and to interact in appropriate ways in a variety of different cultures (Bennett and Bennett, 2004). Moreover, it is a multifaceted state of being - which includes knowing that there are cultural differences, what they are, and how to apply that knowledge. Simply put, it is the ability to adapt to different cultural settings, the essence of being bicultural (Ashwill and Hoâng Oanh, 2009). In other words, it is a set of capacities and abilities used in multicultural contexts as the ability to communicate effectively with people having different culture, behaviour, traditions and values or the capacity to identify behaviours that are "culturally driven" and that allow us to completely understand a person we are communicating with.

Being intercultural competent means to acquire a wider vision of the world, be more efficient in our interactions with other speakers, have more chances for personal and professional advances. According to Holden (2002), the key elements to bring about intercultural competence are participation, interaction, communication, networking, collaborative learning, knowledge transfer, experiences and values, creation of a cooperative climate. Moreover, it includes the ability to gain and interpret new information, approaches, practices and products of a different cultural context (Koehn \& Rosenau, 2002).

The theoretical framework shows that intercultural competence is partially inherited and partially gained through learning. The inherited personality traits can be empathy, open-mindedness and emotion: intercultural situations are often linked to emotions, should those be positive or negative. On the other hand, individuals can acquire intercultural competences through a learning process involving critical reflection and practical experience (Hofstede, 1994).

The development of intercultural competence requires a learning process that is also accompanied by the conscious development of our own value system involving the cognitive, affective and behaviour-oriented level. This would allow any person to act properly and spontaneously in an intercultural situation or context. Moreover, the development of the intercultural competence is an active process of continuous learning which implies even a transformation of the person's identity while experiencing other different cultures or group interactions, in the own country or abroad (Richards, 2006).

Intercultural competence involves a wide range of attitudes, skills, knowledge and behaviours (Kim, 2002; Deardorff, 2006; Chen \& Starosta, 1997b).

Besides the basic components of intercultural competence, a successful intercultural person is expected to be flexible, motivated, tolerant and adaptable, to use appropriate linguistic means and communication styles, to listen, observe and adjust to different situations and behaviours.

The intercultural competence regenerates experience but going beyond that and creating a different knowledge, a sort of "forth talent" (Reggio, 2009). It gets going in critical cultural situations when people resort to their unknown and original resources (Onorati, Bednarz, Comi, 2011). Literature refers to the concept of intercultural competence as inclination, sensitivity, attitude, character or personal features and qualities such as respect, open-mindedness, empathy and curiosity. The intercultural competence is about an experience, both socially and communicatively oriented, starting with the concrete relation with the other, different from us, within a shared space where other elements meet through a mediation (Fabris, 2002). The complexity of this process is due to the fact that intercultural competences take into account cognitive, motivational and behavioural aspects. When an intercultural relation takes place, specific competences activate (Müller, 1993):

- awareness about possible communication misunderstandings linked to culture and affecting both the relation and the behaviour;

- awareness about different ways of thinking, acting, behaving due to the specific culture and the cognitive frames;

- availability and ability to acquire other cultural perspectives;

- knowledge of different cultural dimensions;

- awareness about the drivers of intercultural communication;

- language and communicative competence.

Such competences are the result of communicative, interactive, behavioural and language abilities. Risager (2007) conceptualised a model of intercultural competence where linguistic competences (languastructural, languacultural competences and interpretation), above all, are prevalent. Moreover, most models of intercultural competence indicate "communicativeness" as core competence (Kim, 1993; Heyward, 2002).

Meeting the difference implies acting competently, in order to communicate, share, mediate, accept, include effectively, bearing in mind that diversity helps to discover both what makes us unique and what joins us. 


\section{Conclusions}

Language is our primary resource to communicate and build social relations. Language is what use to express ourselves, our thoughts and our identity but, noticeably, it is not sufficient within multicultural contexts where we need to interact with people having a different cultural background. We may speak fluently and master another language but we may, anyway, run into misunderstandings or cultural clashes. Nowadays, the globalised world is also a multicultural world but a passive acceptance of the other is not enough: an intercultural way of interacting is necessary. That is why language and communication are more and more a matter of culture, or better, of intercultural competence. As already stated, a different view of the world comes up when we come into contact with a speaker of a different language: communication cannot be considered only as a simple information exchange but it should be regarded for its capacity of creating and maintaining relations according to the encountered cultural context. Culture is a complex dimension. It defines they way we see the world, affecting our interactions and perceptions, our verbal and non-verbal language, our identity. Culture and communication affect each other. Communication itself always arises and happens within a culture. Our own culture shows off through communication and vice versa culture teaches us how to behave and communicate appropriately. Becoming culturally competent is a process of continuous learning supported also by experience. To communicate and interact effectively with other people, we need a relevant language and communicative competence but also, and above all, other numerous dimensions such as empathy, curiosity, open-mindedness, respect, emotion, flexibility, tolerance, motivation, awareness, all included in what we may define intercultural competence. It is a sort of "forth talent" to be used in critical cultural situations to face unknown and original contexts.

Research shows that we possess, consciously or unconsciously, intercultural competences, strengthened through a continuous learning process, a critical reflection and experience, too.

The world around us is inevitably changing, is evolving and becoming more and more multicultural. It means that we need to adjust inevitably and become more competent, acquiring an intercultural perspective. A significant culture of diversity should be encouraged in order to stress why we are so unique and why we are so different, or simply distant. Intercultural competence may be a bridge to go near that diversity, to approach it effectively and positively, not just accepting but above all respecting and sharing it. Intercultural competence involves both language and communicative dimensions, going beyond and encouraging and enhancing what we may already possess and what we may still acquire. There is a great variety of dimensions and elements that people need to handle in order to be considered competent. Developing intercultural competences inevitably transforms us because we increase perceptions of our own culture and other people's cultural background. We gain awareness of who we are, we become more flexible, sensitive and open to other cultures, we have a more successful communication building meaningful relations with other cultures.

\section{References}

Aldridge, M.G. (2002). What is the basis of American culture? Intercultural Communication 5 (27), from http://www.immi.se/jicc/index. php/jicc/article/view/137

Alptekin, C. (2002). Towards intercultural communicative competence in ELT. ELT Journal 56 (1), 57-59.

Ashwill, M. A., \& Hoâng Oanh, D. T. (2009), Developing globally competent citizens: The contrasting cases of the United States and Vietnam. In D.K. Deardorff (Ed.), The SAGE Handbook of Intercultural Competence (pp. 142-157), Thousand Oaks, CA, Sage Publications.

Balboni, P. (2006). Intercultural Communicative Competence: a model. Perugia, Guerra Edizioni

Bennett, M.J., \& Bennett, J.M. (2004). Developing intercultural sensitivity: an integrative approach to global and domestic diversity. In D. Landis, J.M. Bennett, M.J. Bennett (Eds.) Handbook of Intercultural Training (pp.147-165), Thousand Oaks, CA, Sage Publications.

Bonvillain, N. (2003). Language, culture and communication: the meaning of messages. New York, Prentice Hall.

Boyatzis, R. E. (1982). The Competent Manager. New York, John Wiley

Brown, M.R. (1989). Starting from scratch. London, Bantam.

Byram M., Nichols A., Stevens D. (2001). Developing intercultural competence in practice. Bristol, Multilingual Matters

Chen, G. M., \& Starosta, W. J. (1997b). A review of the concept of intercultural sensitivity. Human Communication, 25(1), pp. 1-16.

Cross, T., Bazron, B., Denni,s K., \& Issacs, M. (1989). Towards a culturally competent system of care. Washington DC, Georgetown University Child Development Centre, CASSP Technical Assistance Center.

Deardorff, D.K. (2006). The Identification and Assessment of Intercultural Competence as a Student Outcome of Internationalization at Institutions of Higher Education in the United States. Journal of studies in international education 10 (3), 241-266.

Fabris, A. (2002). Comunicazione e mediazione interculturale. Prospettive a confronto. Pisa, Edizioni ETS.

Fraser E., Schalley A. C. (2009). Communicating about communication: intercultural competence as factor in the success of interdisciplinary collaboration. In Australian Journal of Linguistics 29 (1), 135-155. 
Gudykunst, W., \& Kim, Y.Y. (1995). Communicating With Strangers: An Approach to Intercultural Communication. In J. Stewart (ed.), Bridges Not Walls pp. 429-442. New York, McGraw-Hill.

Hall, E.T., \& Hall, M.R. (1990). Understanding Cultural Differences. Minneapolis, Consortium Book Sales \& Dist

Hall, S. (1997). Introduction to Representation: cultural representations and signifying practices, Thousand Oaks, CA, Sage Publications.

Haslett B. (1989), Communication and language acquisition within a cultural context, in Ting-Toomey S., Korzenny F. (eds) Language, communication and culture: current directions, Thousand Oaks, CA, Sage Publications.

Heyward, M. (2002). From international to intercultural: redefining the international school for a globalised world. In Journal of research in international education 1 (9), 9-32.

Hymes, D.H. (1988). Vers la compétence de communication. Paris, Didier.

Kim, Y. K. (1993). Cross-cultural adaptation: An integrative theory. In R. L. Wiseman, J. Koester (eds.), Intercultural communication theory pp. 3-15. Thousand Oaks, CA, Sage Publications.

Kim, Y. Y. (2002). Adapting to an unfamiliar culture: An interdisciplinary overview. In

W. B. Gudykunst \& B. Mody (2nd Eds.), International and Intercultural Communication pp. 259-277. Thousand Oaks, CA. Sage Publications.

Le Boterf, G. (2000). Construire les Compétences Individuelles et Collectives. Paris, Editions d'Organisation.

Mays, R., Siantz, M. \& Viehweg, S. (2002). Assessing Cultural Competence of Policy Organizations. Journal of Transcultural Nursing 13 (2), 139-144.

Morillas, M. (2001). Developments in culture teaching theory. In G. Sánchez, Present and future trends in TEFL (pp. 293-320), Almería, Servicio de publicaciones de la universidad de Almería.

Morley, M. J., Cerdin J. (2010). Intercultural competence in the international business arena. In Journal of Managerial Psychology 25 (8), 805-809.

Müller, B.D. (1993). Interkulturelle kompetenz. Annäherung an einen Begriff, Jahrbuch Deutsch als Freemdsprache, 19. In AA.VV., Multilinguismo e interculturalità, Atti del Convegno, Milano, Centro linguistico Bocconi.

Onorati, M.G., Bednarz F., \& Comi, G. (2011). Il professionista interculturale. Roma, Carocci.

Perry, L. B., Southwell L. (2011). Developing intercultural understanding and skills: models and approaches. London, Routledge.

Reggio, P. (2009). Apprendimento esperienziale: fondamenti e didattiche. Milano, Edizioni Isu Università Cattolica.

Richards, J.C. (2006). Communicative language teaching today. New York, Cambridge University Press.

Risager, K. (2007). Language and culture pedagogy: From a national to a transnational paradigm. Clevedon, Multilingual Matters.

Savignon, S. J. (1972). Communicative Competence: An Experiment in Foreign Language Teaching. Philadelphia, The Centre for Curriculum Development

Spitzberg, B.H., Cupach, W.R. (1984). Interpersonal communication competence, Thousand Oaks, CA, Sage Publications.

Stewart, S. (2006). Cultural Competence in Health Care. Sydney, Diversity Health Institute.

Ting-Tomey, S. (1999). Communicating across cultures. New York, The Guilford Press.

Valdes, J.M. (1986). Culture bound: bridging the cultural gap in language teaching. Cambridge, Cambridge University Press. 